\title{
Cadmium and copper accumulation in the common mussel Mytilus edulis in the Western Scheldt estuary: a model approach
}

\author{
R. J. F. van Haren ${ }^{1,3}$, J. van der Meer ${ }^{1,4} \&$ M. B. de Vries ${ }^{2}$ \\ ${ }^{1}$ Rijkswaterstaat, Tidal Waters Division, P. O. Box 20907, 2500 EX Den Haag, The Netherlands, ${ }^{2}$ Delft \\ Hydraulics, P. O. Box 177, 2600 MH Delft, The Netherlands; ${ }^{3}$ Present adress: Theoretical Biology, Free \\ University, De Boelelaan 1087, $1081 \mathrm{HV}$ Amsterdam, The Netherlands; ${ }^{4}$ Present adress: Netherlands \\ Institute of Sea Research, P. O. Box 59, 1790 AB Den Burg, Texel, The Netherlands
}

Key words: Mytilus edulis, accumulation, mathematical model cadmium, copper, speciation

\begin{abstract}
The Western Scheldt of the Dutch Delta area is severely contaminated with trace metals. Accumulation models of trace metals in the mussel Mytilus edulis are required to predict the biological efficiency of reductions in the metal and organic matter load. Two models are constructed: a black-box model and a physiologically structured model. The black-box model predicts metal accumulation in mussels from uptake and elimination parameters. The physiological model attempts to improve predictions by taking into account the kinetics of individual uptake and elimination routes. These in turn, are taken as depending upon two more general physiological processes, the ventilation rate and the metabolic rate. Metal uptake via food and water are expressed as relative fractions. Metal input is differentiated into particulate adsorbed, and dissolved species.

The reliability of the two models is evaluated by comparing predicted concentrations for mussels with measurements. Model predictions for copper deviate less than $100 \%$ from measured concentrations, but neither model appears to predict cadmium concentration with sufficient accuracy since deviations of more than $100 \%$ occured. The introduction of physiological refinements did not improve performance. Food mediated contributions for cadmium and copper to total body burden had been overestimated in the model by a factor of 100 when compared to literature values. The physiological model did predict that the ratio of food mediated contribution to total body burden is probably different for cadmium and copper and decreases with increasing salinity for both. As yet there are no measurements available to confirm such predictions.

We conclude that additional laboratory experiments should be done for a better understanding of why there is poor agreement between the few field observations and the simulations. In these experiments mussels grown under different environmental condition can be tested for their accumulation capacity of trace metals. More field observations are needed.
\end{abstract}

\section{Introduction}

The Western Scheldt estuary of the Dutch Delta area has severe contamination problems both for trace metals and organic micropollutants. The cadmium load at the Dutch-Belgian border was 10 tons/year in 1981 and 6 tons/year in 1987. The copper load was 62 to 73 tons/year for 1981 and 1987. Consequently, cadmium concentrations in the common mussel Mytilus edulis in Western 
Scheldt reached values of $874 \mathrm{nmol} \mathrm{g} \mathrm{adw}^{-1}$ (ashfree dry weight) in 1981 and $22 \mathrm{nmol} \mathrm{g} \mathrm{adw}^{-1}$ in 1987. Copper concentrations obtained values of $346 \mathrm{nmol} \mathrm{g} \mathrm{ADW}^{-1}$ in 1981 and $197 \mathrm{nmol} \mathrm{g}$ $\mathrm{adw}^{-1}$ in 1987. These concentrations are considerably higher than the background levels of $5.78 \mathrm{nmol} \mathrm{g} \mathrm{adw}^{-1}$ for cadmium and $122 \mathrm{nmol} \mathrm{g}$ $\mathrm{adw}^{-1}$ for copper derived from measurements in 1981 at Killary Harbour near Leenaun in Western Ireland (DeKock \& Marquenie, 1981). These values should be compared with effect concentrations of cadmium for mussels which approximate $44 \mathrm{nmol} \mathrm{g} \mathrm{adw}^{-1}$ (Marquenie \& Vethaak, in press) and to lethal concentrations of copper for mussels which approximate 790-940 nmol g $\mathrm{adw}^{-1}$ (DeKock, 1986). It is evident that metals, and in particular cadmium, are cause for great concern.

In 1987 the Dutch government started a project to investigate the distribution and behaviour of contaminating substances in the estuary and produce a Water Quality model. This model will derive results from a series of modules related to water and particle transport, to chemical distribution and to bio-accumulation of metals. The present paper concerns the development and evaluation of two bio-accumulaten models, which differ according in the degree to which biological processes have been taken into account as variables influencing uptake and elimination of metals. Both are evaluated, using timeseries field data for dissolved and adsorbed metal concentration as the input for the simulation of cadmium and copper concentrations in mussels. The results are then compared to field measurements.

\section{Model assumptions}

In designing these models a number of assumptions were made about the routes of metal uptake in mussels and the nature of bio-available metal species in relation to specific uptake route.

\section{Uptake route}

In the mussel, the main metal species are the water dissolved species, taken up via the gills and particle adsorbed metals ingested with food.
Views on the relative importance of these two uptake routes have changed in the literature with time. Initially metal uptake with food was considered the major source for body burden (Pentreath, 1973; George, 1980), or of equal importance to that of via the gills (Schulz-Baldes, 1974). Recent work however has pointed to metal uptake via the gills as the major contributor to body burden (Kohler \& Riisgard, 1982; Borchardt, 1983; King \& Davies, 1987 and Riisgard et al., 1987).

\section{Bio-available trace metal species}

The nature of the bio-available species will depend on the mechanism of uptake (George, 1980; Baudo, 1982; Luoma, 1983). Available data differ according to, whether metal uptake via the gills is considered to occur through passive diffusion (George, 1980; Carpene \& George, 1981; Simkiss, 1983; Langston \& Bryan, 1984; Viarengo et al., 1987) or to active, carrier mediated transport (Janssen \& Scholz, 1979). Since ATP-inhibitors appear unable to affect cadmium uptake via the gills (Carpene \& George, 1981), the assumption of passive diffusion seems the more likely one. In this case, the main metal uptake species to consider, should be the small ionized froms, the chlorides and the hydroxides, since in studies on solubility of metals in artificial bilayers solubility is associated with the above (Simkiss, 1983). This fits with the finding that increasing salinity (chlorinity), which is associated with decreasing ionization of cadmium, does decrease its toxicity (Engel \& Fowler, 1979). The outcome of experiments in which NTA (nitrilotriacetic acid) was used to replace chloride as the metal complexing agent suggested the present survival of the grass shrimp Palaemonetes pugio is a function of free cadmium ion and not of total cadmium concentration (Sunda et al., 1978; Salomons \& Forrstner, 1984. The toxicity and bioavailability of copper has also been associated with the ionized species (Engel et al., 1981).

\section{Particulate matter}

All previous arguments support the assumption that for the gills, the bio-available fraction of 